Entrevista com Ítalo Campofiorito: a trajetória de um modernista.

Revista Ensaios, vol. 15, jul-dez de 2019.

\title{
Entrevista com Ítalo Campofiorito: a trajetória de um modernista.
}

\author{
Carlos Douglas Martins Pinheiro Filho ${ }^{1}$
}

A presente entrevista, editada especialmente para este volume da Revista Ensaios, foi realizada em 2016 com o propósito inicial de compor o material básico de minha tese de doutorado. Entretanto, em 26 de maio de 2020, diante do contexto de falecimento do professor Ítalo Campofiorito, se fez necessário amadurecer o propósito de trazê-la a público não apenas como referência de uma pesquisa, mas como memória da história de vida desse importante intelectual brasileiro.

A trajetória de Ítalo Campofiorito se confunde com a história da cidade de Brasília, pois foi ele um dos arquitetos responsáveis pela sua construção, atuando conjuntamente com Oscar Niemeyer, assim como assinou a posterior patrimonialização do plano piloto da cidade, no ano de 1990, quando assumiu a direção do Patrimônio Histórico e Artístico Nacional. Então, Ítalo Campofiorito tornou-se professor titular da Universidade de Brasília (UnB), colaborando com Darcy Ribeiro na fundação dessa universidade e com a conformação do campo de estudos específico sobre patrimônio no Brasil.

$\mathrm{Na}$ experiência do primeiro mandato de Leonel Brizola e Darcy, Ítalo tombou prédios, logradouros e áreas verdes por todo o Estado do Rio de Janeiro. Durante a gestão de Jorge Roberto Silveira como prefeito de Niterói/RJ, foi secretário de cultura e uma figura central na conformação do Museu de Arte Contemporânea (MAC-Niterói).

Ítalo Campofiorito tomou parte de tantos acontecimentos significativos durante seu tempo de vida que será árdua a tarefa daquele que, por ventura, fazendo justiça a sua

\footnotetext{
${ }^{1}$ Licenciado e Bacharel em Ciências Sociais pela Universidade Federal Fluminense (UFF). Mestre em Comunicação e Cultura pelo Programa de Pós Graduação da Escola de Comunicação (ECO-Pós) da Universidade Federal do Rio de Janeiro (UFRJ). Doutor em Sociologia pelo Programa de Pós-graduação em Sociologia e Antropologia (PPGSA) da Universidade Federal do Rio de Janeiro (UFRJ). Professor de Sociologia da Fundação de Apoio a Escola Técnica (FAETEC) e editor adjunto da Revista Ensaios do Programa de Pós-graduação em Sociologia (PPGS) da Universidade Federal Fluminense (UFF). Brasil, Niterói, Rio de Janeiro. cdouglasmartins@gmail.com.
} 
Entrevista com Ítalo Campofiorito: a trajetória de um modernista.

Revista Ensaios, vol. 15, jul-dez de 2019.

trajetória social, busque realizar o registro e organização das ações desse importante personagem em uma biografia. Esta entrevista, além de ser um pequeno registro de seu pensamento, sendo assim, significativa para história intelectual do país, também constitui uma homenagem póstuma ao ser humano inquisitivo, astuto e gentil, que aos 84 anos ainda mantinha a voz empostada e a postura altiva, com uma tremenda força de pensamento.

O primeiro encontro para realizar está entrevista foi no dia 3 de outubro de 2016, no Restaurante Deli 43 - Pavelka $^{2}$, no Leblon, bairro onde Ítalo residia na época. O local foi sugerido Ítalo com o propósito de tomarmos um café da tarde durante a entrevista, pois seria um local frequentado e conhecido por ele.

Conte um pouco sobre sua experiência na construção de Brasília em conjunto com Oscar Niemeyer.

"Eu não o conhecia, mas fui muito insistente, fiquei dias indo a seu escritório para convencê-lo de me empregar. Um dia ele falou comigo e logo em seguida estava em Brasília. Foi uma aventura!".

\section{Essa experiência acabou te aproximando de Niemeyer?}

"Sim, viramos amigos, frequentava a casa dele, os encontros e reuniões que fazia".

Fale sobre a sua relação com Anna Maria Niemeyer, que além de filha de Oscar, era curadora da coleção de João Sattamini.

"Anna Maria era uma grande amiga, moramos juntos em Brasília e sempre nos encontrávamos na casa de Oscar, eu tinha saído do Rio para trabalhar com ele e estava sempre lá na casa dele em reuniões e almoços. Nossa amizade começou ai e continuamos amigos quando retornei ao Rio. Na época, ela trabalhou com decoração de interiores dos prédios projetados por Oscar e selecionou toda mobiliária. Depois, virou galerista e curadora de arte".

\footnotetext{
${ }^{2}$ Rua João Lira, 97, Leblon, Rio de Janeiro/RJ.
} 
Entrevista com Ítalo Campofiorito: a trajetória de um modernista.

Revista Ensaios, vol. 15, jul-dez de 2019.

\section{Como se tornou Secretário de Cultura de Niterói?}

"Eu já tinha a experiência com Brizola e conhecia Claudio Valério Teixeira de infância. O pai de Claudio conservador, defendia uma pintura acadêmica, tradicional, e o meu pai era modernista e comunista. Mas nós sempre fomos amigos. Claudio estava a trabalhando na reforma do Teatro Municipal, ele é pintor e trabalha com restauração, é um grande restaurador. Então, ele falou com Jorge Roberto e Jorge me fez o convite para ser Secretário de Cultura”.

\section{Como arquiteto, como você vê o MAC?}

"O MAC se destaca pela pregnância de suas formas, o museu é emblemático, circular, as pessoas chamavam de disco voador. Penso que Oscar criou o museu a partir do homem. Ele era um grande humanista e, também, sempre foi comunista. A rampa, que eu chamei de ciclorama, é uma grande metáfora disso, pois ela gira entorno da obra do homem, você circula e vê a cidade, mas é espiral, você retorna para o início, mas não está no mesmo lugar".

\section{A obra durou cinco anos para ser concluída, como foi isso?}

"Foi uma obra muito difícil, cavaram o promontório até ao nível do mar para fazer a sustentação. Foram 5 toneladas de matéria de escavação".

Mas ali não seria uma região com cavernas, que necessitavam do escoramento de vigas para sustentação do peso do museu?

"Não, não tem nada disso. Isso foi uns dos questionamentos sobre a obra que teve na época, mas o que aconteceu é que cavaram até o nível do mar para fazer a sustentação. Demorou muito para preparar o terreno".

A conversa se encaminhou para temas da atualidade. Ítalo repetia que "essa crise" tinha abatido a prefeitura e toda política do país, prosseguindo com analises de conjuntura. Ficamos conversando longamente sobre esse assunto, que parecia do seu interesse, apesar de a todo o momento afirmar que "estava muito velho para ter esperança e fazer alguma coisa". Logo se sentiu cansado e pediu para encerrar o encontro, disse que queria retornar 
Entrevista com Ítalo Campofiorito: a trajetória de um modernista.

Revista Ensaios, vol. 15, jul-dez de 2019.

para casa e seus afazeres.

No final de outubro, nos encontramos novamente no Pavelka, Ítalo parecia mais à vontade e confortável com a minha presença.

\section{Iniciei perguntando sobre a experiência com Darcy Ribeiro.}

- "Eu trabalhei na UnB na época em que Darcy era reitor da universidade e o conheci. Darcy queria que Oscar no corpo docente da universidade, mas ele me indicou. Fiquei lá um tempo, depois voltei ao Rio em 1970, pois tinha pedido exoneração da UnB em conjunto com um grupo de professores, por conta da perseguição da ditatura. Darcy havia se exilado em abril de 1964 no Uruguai, mas muitos colegas da universidade ficaram no país, eu fui um deles. Na verdade, creio que não me perseguiram tanto por ser próximo a Oscar, pois a ditadura não queria briga com Oscar. Também por conta de Oscar fui chamado para o corpo docente da UnB, pelo próprio Darcy, que a princípio não me agradava, mas que depois ficamos amigos. Ele queria agradar Oscar e achava que me convidando para lecionar na universidade seria uma maneira de fazer isso. Com o tempo fomos reconhecendo um ao outro, ficamos amigos".

\section{Como foi o retorno ao Rio?}

"Quando cheguei ao Rio na década de 1970, fui trabalhar com planejamento urbano e depois com patrimônio e ingressei no INEPAC (Instituto Estadual do Patrimônio Cultural) durante o Governo de Chagas Freitas. Quando Brizola ganhou a eleição para o governo do estado, cheguei a ser questionado por estar trabalhando no governo de Chagas Freitas, mas eu não era chaguista! Lembro-me de uma conversa com Darcy no período, ele disse: "você pode ter a opinião que quiser, pois é muito bom na sua área e eu quero que você trabalhe conosco'. Foi assim que comecei a dirigir o órgão".

Você teve essa experiência como Secretário Estadual de Cultura junto com Darcy, no governo de Brizola, o que tem a dizer sobre isso?

"Nessa época iniciamos um processo de ampla patrimonialização em todo o estado, de prédios no centro do Rio até áreas costeiras imensas no sul fluminense!! Darcy era 
Entrevista com Ítalo Campofiorito: a trajetória de um modernista.

Revista Ensaios, vol. 15, jul-dez de 2019.

muito ativo e dificilmente rejeitava totalmente uma ideia, um exemplo foi o tombamento da Pedra do Sal!”.

Não era comum tombar áreas costeiras como patrimônio histórico e cultural, não houve resistência?

"Quando sugeri para Darcy tombar as regiões costeiras no sul fluminense, em Paraty, nunca havia feito nada igual na área de patrimônio, mas Darcy logo foi convencido quando falei que a área era dominada por grileiros de terra e que, possivelmente, no futuro, seria toda da especulação imobiliária. Então, Darcy fez de tudo para tombar".

O que você pode dizer sobre sua experiência com Brizola?

- "Brizola era um líder carismático e popular, fez muitas es colas e creches, sabia compreender as necessidades da maioria da população".

\section{Você é ou foi filiado ao PDT (Partido Democrático Trabalhista)?}

"No início eu era independente, de esquerda, filho de comunista, mas crítico ao comunismo pela experiência com o socialismo real. Porém, durante o governo de João Sampaio, tive que me filiar ao PDT para continuar com minhas atividades no âmbito da cultura de Niterói”.

\section{Como foi sua gestão como Diretor do MAC-Niterói?}

"Havia muita coisa a ser feita. Sugeri a criação de uma biblioteca que reunisse todos os catálogos e outros livros doados para o museu. Havia muito trabalho com a Coleção, de catalogação e conservação. Fizemos muitas exposições também nesse período".

\section{Como você avalia o comotado dos objetos de arte de João Sattamini?}

"O comodato tinha a promessa de doação das obras para a prefeitura, era uma das clausulas do contrato, com a sua morte João Sattamini doaria ao poder público. Mas o comodato foi descumprido desde o princípio, pois diversas clausulas como a catalogação completa das obras emprestadas, nunca foi cumprida, a pouco que foi inventariado todas 
Entrevista com Ítalo Campofiorito: a trajetória de um modernista.

Revista Ensaios, vol. 15, jul-dez de 2019.

as peças, se não me engano. Mesmo Jorge Roberto nunca acreditou no comodato. Tem obras ali muito valorizadas no mercado e o comodato não impede que os herdeiros queiram dar destino diferente à coleção. Nós achávamos excelente que Sattamini quisesse expor sua coleção e isso valorizava a cidade, trazia turismo, o que agradava Jorge, mas nunca tivemos ilusão. Creio que Sattamini e seus herdeiros possam doar parte, mas não toda a coleção emprestada".

Então, não é a questão legal do comodato que garante a relação entre o colecionador e a prefeitura?

"Não, posso dizer claramente que não. Por exemplo, hoje, o contrato expirou, mas Sattamini não tira sua coleção de lá. No museu ele sabe que as obras serão expostas, catalogadas e conservadas. Lá a coleção permanece valorizada”.

\section{Mas então, o que garante o empréstimo?}

"É o interesse mútuo, da prefeitura que sabe do valor da coleção e que isso traz valor para a cidade, via turismo. E de Sattamini que não precisa se preocupar em arranjar um lugar para as obras e nem investir em conservação. Parece que antes de empresar a coleção para o MAC ele mantinha um apartamento só para abrigar sua coleção!”.

Pelo que eu compreendi lendo seus relatos, é que você foi o interlocutor da prefeitura com Oscar Niemeyer. Como era a relação de Jorge com Oscar?

"Oscar admirava muito Jorge Roberto e ficava um pouco frustrado que Jorge pedia a mim para falar com ele. Oscar falava: por que ele não vem falar comigo? Mas Jorge acreditava que era melhor que eu fizesse, mas logo eles se encontraram e criaram uma boa relação".

Você é filho de pintores, isso foi importante para o caminho que você seguiu?

“Sim, sim, nesse sentido eu tive berço. Minha mãe era pintora, muito talentosa, e meu pai além de pintor era arquiteto e comunista, o que foi muito importante. Meu avô, Pietro, também era pintor e arquiteto, era italiano, mas não tinha uma origem abastada. Veio para o Brasil e se instalou no Pará, onde trabalhou como arquiteto. Depois, veio para 
Entrevista com Ítalo Campofiorito: a trajetória de um modernista.

Revista Ensaios, vol. 15, jul-dez de 2019.

o Rio (1913), projetou alguns prédios e venceu o concurso para a sede da Cruz Vermelha, hoje tombada pelo patrimônio cultural. Foi morar em Niterói e construiu a Praça da República $^{3}$ (antes chamada praça D. Pedro II). Ao aposentar-se do serviço público do Estado do Rio, foi nomeado diretor fundador do Museu Antônio Parreiras, em Niterói”.

\section{Qual a relação da sua família com a cidade de Niterói/RJ?}

"Meu pai fez a Escola Nacional de Belas Artes e ganhou um prêmio de viagem para a Europa. Passou uma temporada em Paris, onde eu nasci. Quando voltou se tornou professor de desenho da Escola Nacional de Belas Artes. Minha mãe também era pintora, excelente por sinal. A família tinha origem alemã. Desde meu avô temos uma relação próxima com a cidade".

\footnotetext{
${ }^{3}$ A Câmara Legislativa, o Fórum, o Liceu e a Polícia do Estado viraram suas novas sedes inauguradas entre 1917 e 1919, sendo a Biblioteca Pública do Estado, inteiramente a cargo de Pietro Campofiorito, construída mais tarde e inaugurada em 1935, dez anos depois da Praça propriamente dita. Todo o conjunto está hoje tombado pelo INEPAC-RJ.
} 